\title{
Progress of Biochemistry
}

\section{Annual Review of Biochemistry}

Edited by James Murray Luck. Vol. 6. Pp. ix + 708. (Stanford University P.O., Calif.: Annual Review of Biochemistry, Ltd.; London: H. K. Lewis and Co., Ltd., 1937.) 5 dollars.

$\mathrm{D}^{\mathrm{n}}$ R. J. M. LUCK and his associates produced the "Annual Review of Biochemistry" for 1937 in ample time for the commencement of the new academic term, when research workers and advanced students, refreshed by their vacation, are eager to achieve new conquests in this field. The present rate of progress is amazing-10,000 papers were abstracted in the previous yearthough it is quality alone which matters and one could wish for an etiquette among workers which forbade publication until substantial achievement could be reported. Unfortunately, to-day in the hustle for priority the reverse happens and far too much immature work is published.

We find the quality of the reviews themselves to be improving; they enable the reader to take a definite point of view instead of being a mere recital of results.

With so much available for comment, the reviewer is embarrassed in his choice. First mention may, perhaps, be made of two articles of a timely nature-a sound policy of the editor. One of these deals with the biochemistry of fish : the other with the application of microchemistry to biochemical analysis, entrusted to C. M. McKay of Ithaca, N.Y., and P. L. Kirk of Berkeley, California, respectively.

Fish have hitherto been rather neglected by the chemist, but their culture on the large scale for culinary and stream-stocking purposes has made it more easy to experiment with them-in the United States there are seven hundred fish hatcheries. There is a great species difference among fish, and the trout, most widely studied, conduct their life processes at very low temperatures. A systematic study of growth and physiological problems connected with fish is now under way, and with so much material available and experimentation relatively easy, very definite results may be expected to accrue.

Every major problem of the chemist has been furthered by the use of micromethods: in fact without such the science to-day would be nothing like so far advanced. The name of Fritz Pregl of Graz, who started the development, must stand high on the roll of honour.
In all, the volume contains 28 reviews by 35 authors, the subjects being classified as is now customary. There is a certain amount of overlapping or duplication with substances which come under two headings, but this is all to the good at the present time. An example is afforded by the co-ferments now described as phosphopyridine nucleotides, the nature of which has been at last worked out-their discovery by Sir Arthur Harden thirty odd years ago in connexion with cell-free fermentation aroused a lot of interest. They consist of a pyridine derivative, namely, nicotine acid amide, adenine, two molecules of a sugar, ribose, together with two or three molecules of phosphoric acid, according to their origin. Warburg and a number of other workers have been active in this field.

An attractive review by $R$. Schoenheimer and E. A. Evans of Columbia treats the chemistry of the steroids, a new term proposed for compounds related to cholesterol to include the sterols proper, the bile acids, cardiac aglycones, toad poisons, saponins, and sex hormones; these form as diverse and remarkable a group of natural substances as can well be imagined, and it is a great achievement largely to have cleared up their problems. Progress has been rapid this last three years since the revision of the old formulæ; the group is uniquely characterized by dehydrogena. tion with selenium to aromatic hydrocarbons in which the original cyclic carbon skeleton is intact.

Another biochemical field which is assuming increasing importance is that of sulphur compounds, reviewed by $\mathrm{V}$. du Vigneaud and $\mathrm{H}$. M. Dyer of Washington. Biological material has now yielded glutathione, methionine, ergothionine, vitamin B, djenkolic acid, asterubin and heparin, to which must be added a new adrenal compound, $\mathrm{C}_{4} \mathrm{H}_{10} \mathrm{O}_{3} \mathrm{~S}$, the constitution of which has been confirmed by synthesis. Much interest attaches also to the chemical behaviour of the sulphur of proteins.

It would be easy to extract examples of marked progress from every review but space restricts us to final mention of the carotenoid pigments, of which a considerable number of new ones have been isolated from land and water plants largely as the result of the ease of isolation, purification and identification which the newer methods of adsorption, absorption and microchemical analysis have brought. There can be no active biochemist who can afford not to keep this book on his desk.

E. F.A. 